\title{
Overweight, Obesity and Chronic Kidney Disease
}

\author{
Stephen M.S. Ting Harikrishnan Nair Irene Ching Shahrad Taheri \\ Indranil Dasgupta
}

Renal Department, Birmingham Heartlands Hospital, Birmingham, UK

\section{Key Words}

Overweight • Obesity · Kidney disease, chronic •

Cardiovascular disease

\begin{abstract}
The sharp rise in the prevalence of chronic kidney disease (CKD) that parallels an increase in the prevalence of obesity in the recent years is a cause for great concern. CKD increases the rate of cardiovascular disease (CVD), development of end-stage renal disease, and leads to premature death. Although no direct causality link between obesity and CKD can yet be established, this appears highly likely. CKD should be regarded as a major complication of overweight and obesity, regardless of whether the association was independent or through the influence of diabetes, hypertension, CVD, metabolic syndrome and high fructose intake. We review the literature on the complex but positive association between obesity and CKD, the pathological effect of excess adiposity in kidney injury and the potential role of weight reduction therapy in reducing the burden of CKD.
\end{abstract}

Copyright $\odot 2009$ S. Karger AG, Basel

Chronic kidney disease (CKD) has a major impact on patients, health services and society. CKD increases the risk of cardiovascular disease (CVD) [1], hospitalization $[2,3]$, and the development of end-stage renal disease (ESRD) [4]. A systemic review of 39 studies that included more than 1 million patients found an increase in the relative risk of all-cause mortality in non-dialysis-dependent CKD patients; the absolute risk of death appeared to increase exponentially with decreasing renal function [2]. Thus, it is essential to identify risk factors for the development and progression of CKD.

In recent years, there has been an alarming rise in the prevalence of CKD that has paralleled the increase in the prevalence of obesity, especially in the Western world [5]. In the last decade, the prevalence of obesity in Great Britain has almost doubled with the national survey showing the proportion of obese individuals to increase from $13.2 \%$ of men in 1993 to $23.7 \%$ in 2006 and from $16.4 \%$ of women in 1993 to $24.2 \%$ in 2006. It is estimated that by 2010 , $75 \%$ of men and $58 \%$ of women in England could be classified as overweight or obese [6]. The World Health Organization (WHO) defines normal body weight using the body mass index (BMI) as a BMI of 18.5-24.9, overweight as BMI ranging from 25 to 29.9 and obesity as BMI of $\geq 30$ [7]. Increasing evidence suggests that obesity is a potentially important contributor to the development of CKD.

Both diabetes mellitus and hypertension are leading causes of ESRD, with the great majority of patients with type 2 diabetes being obese. Several observational studies have demonstrated a consistent association between the risk of CKD and increasing BMI. The majority of these have indicated that the association of obesity and CKD is through the influence of risk factors including diabetes, hypertension and metabolic syndrome (MS) [8-14]. Other studies [15-18], however, have suggested a direct link between obesity and kidney disease.

\section{KARGER}

Fax +4161306 1234 E-Mail karger@karger.ch www.karger.com (c) 2009 S. Karger AG, Basel

$1660-2110 / 09 / 1123-0121 \$ 26.00 / 0$

Accessible online at:

www.karger.com/nec
Dr. Stephen M.S. Ting

Renal Unit, Birmingham Heartlands Hospital

Bordesley Green East

Birmingham B9 5SS (UK)

Tel. +44 121424 2156, Fax +44 121424 1159, E-Mail stephen_ting@yahoo.com 
In the Framingham Heart Study of 2,585 individuals with nearly 19 years of follow-up, traditional cardiovascular risk factors of age, hypertension, diabetes, obesity and tobacco use have been shown to be predictors of new-onset kidney disease [16]. In this US communitybased longitudinal cohort study, patients who were obese at baseline were more likely to have decreased renal function. On multivariate analysis (controlling for age, sex, baseline glomerular filtration rate [GFR], smoking and diabetes status), increased baseline BMI was significantly associated with development of CKD, with an odds ratio of 1.23 (95\% CI 1.08-1.41) for each standard deviation in BMI. Obesity as a predictor for the development of CKD was also demonstrated in 2 larger studies with 5,897 and 11,104 patients, respectively $[8,18]$. Data from the Hypertension Detection and Follow-up Program [8] found the risks of developing CKD at 5 years after adjustment for age, sex, race and diabetes for overweight and obese patients were 20\% (95\% CI 1.04-1.39) and $40 \%$ (95\% CI 1.21-1.65), respectively, compared with normalweight patients. In the large prospective cohort study consisting of healthy male physicians [18], the risk of developing CKD after 14 years of follow-up was approximately $30 \%$ in those who were overweight $(1.32,95 \% \mathrm{CI}$ $1.09-1.61)$ and obese (1.26, 95\% CI 1.03-1.54) after controlling for age, smoking, exercise, alcohol consumption at baseline, parental history of myocardial infarction, diabetes, hypertension, hypercholesterolaemia and coronary artery disease. Analysis of data from the Second National Health and Nutrition Examination Survey (NHANES II) [9] identified an increased risk for CKD in those who were morbidly obese (baseline BMI of $\geq 35$ ). There were 9,082 adults in the NHANES II population and the study covered an average follow-up of 13.2 years. The study found that those with morbid obesity had more than double the risk of CKD $(2.3,95 \%$ CI 1.1-4.9) compared to normal weight individuals, independent of age, sex, race, smoking and physical activity.

It remains unclear, however, whether high BMI is a risk factor for CKD, independent of diabetes and hypertension with some studies showing conflicting results. In a Swedish case-control study (926 vs. 998 patients) [15], men and women with BMIs of $\geq 25$ at ages 20,40 and 60 years had a significant threefold elevated risk of CKD compared with those with BMIs of $<25$. This elevated risk was particularly strong in those with diabetes. Other studies, however, have found no such correlation $[8,18]$. In addition to diabetes, the odds for CKD in obese individuals may also be high in the presence of hypertension or both diabetes and hypertension. A Taiwanese commu- nity-based cross-sectional study of 4,611 adults documented a greater than twofold increased risk of CKD in obese individuals especially in participants who had hypertension and diabetes [19]. The odds were 2.9 (95\% CI 2.11-3.97) and 2.4 (95\% CI 1.68-3.57), respectively. Obese men appeared to have a greater risk than women in some studies $[4,15,17,19]$. In a Japanese cohort of 100,753 adults [17], the cumulative incidence of ESRD was greater than 2-fold in those with baseline BMI of 25.5 or greater compared with adults with baseline BMI of $<21.0$. This association was only noted in men but not women after 17 years of follow-up with the risk being independent of the presence of hypertension. A similar positive association with CKD was seen among overweight and obese men in a population-based study from Singapore [19].

Obesity has not only been suggested to cause renal disease but also appears to accelerate its deterioration. In a retrospective cohort study of 320,252 healthcare-insured participants from northern California who were followed for 15-35 years [14], the rate of ESRD was found to be increasing in a stepwise manner with higher BMIs. This study used the National Heart, Lung and Blood Institute guidelines to define normal weight as a BMI of 18.5-24.9, overweight as a BMI of 25.0-29.9, and subdivided obesity into three classes: I (BMI 30.0-34.9), II (BMI 35.0-39.9) and III $(B M I \geq 40)$ [20]. The age-, sex-, and race-adjusted rates of ESRD increased from 10 per 100,000 personyears among those with normal weight to 108 per 100,000 person-years among those with class III obesity. After adjustment for multiple variables (for follow-up period, age, sex, race, education level, smoking status, history of myocardial infarction, serum cholesterol level, proteinuria, haematuria and serum creatinine level), the relative risk of ESRD compared with adults with normal weight were 1.87 (95\% CI 1.64-2.14) in the overweight group, 3.57 (95\% CI 3.05-4.18) in class I obesity, 6.12 (95\% CI 4.977.54) in class II obesity and 7.07 (95\% CI 5.37-9.31) in those with class III obesity. This significant relationship between the risk of ESRD and elevated BMI persisted after controlling for baseline blood pressure and diabetes status. Some studies have found that certain groups of renal patients who were obese had a particularly high risk of CKD progression. Obesity was identified as an independent risk factor predisposing patients with IgA nephropathy [21] and in allograft recipients $[22,23]$ to a more rapid loss of renal function. An increased BMI may also be more hazardous in patients with reduced renal mass (uninephrectomy or unilateral renal agenesis or a non-functioning kidney) [24]. 
Microalbuminuria has been described as the earliest manifestation of obesity-associated kidney damage and diabetic nephropathy. This is associated with insulin resistance independent of diabetes, a physiology that is not yet fully understood [25]. Obese individuals commonly have increased plasma renin activity, angiotensinogen, angiotensin-converting enzyme activity, circulating angiotensin II (renin-angiotensin-aldosterone system) and renal sympathetic activity. Hyperinsulinaemia, insulin resistance and increased angiotensin II are potent activators for the expression of transforming growth factor- $\beta 1$ (TGF- $\beta 1$ ), a fibrogenic cytokine which contributes to glomerular injury [26]. Microalbuminuria or proteinuria can be attributed to augmented hyperfiltration, a wellrecognised glomerular haemodynamic change in obesity $[27,28]$. Worsening proteinuria in the nephrotic range is frequently followed by a progressive loss of renal function. Focal segmental glomerulosclerosis (FSGS) is the most significant and frequent histological abnormality in proteinuric morbidly obese patients [29-31]. Even though obesity-related FSGS (or obesity-related glomerulopathy, ORG) usually exhibits a less severe proteinuria compared to primary 'idiopathic' FSGS, the long-term prognosis of the former is poor with almost one half ultimately developing advanced renal failure [29]. This observation, however, is from a small study consisting of 15 obese patients with biopsy-proven FSGS compared with a control group of 15 non-obese patients with primary FSGS. Overall, there has been a rise in the incidence of ORG in the past 2 decades which seems to be congruent with the sharp increase in the prevalence of obesity. A large comparative study in United States of 6,818 renal biopsies over 15 years (from 1986 to 2000) found a tenfold increase in the incidence of ORG $(p=0.0001)$ [32]. Presentation was typically one of nephrotic-range proteinuria (48\%) or sub-nephrotic proteinuria (52\%), accompanied by renal insufficiency (44\%). None of these patients with ORG had histological evidence of diabetic nephropathy.

For decades, obesity has been well recognised as a major risk factor for CVD, diabetes, hypertension, hyperlipidaemia and more recently, the MS [33]. All these adverse consequences are well known to be independent precursors to CKD. Thus, weight reduction should have beneficial effects not only in reducing cardiovascular and metabolic complications but also in slowing the progression of $\mathrm{CKD}$ and perhaps delaying or preventing CKD. However, evidence for the latter is scarce. In a small Japanese case series, 25 patients with BMI $>25$ who were hypertensive and microalbuminuric with preserved renal function were placed on a low-calorie diet $(25 \mathrm{kcal} / \mathrm{kg})$ [34] with a significant improvement in microalbuminuria and blood pressure over 1-year follow-up in the 12 patients who achieved a weight reduction of at least $5 \%$. Another case series compared 8 adult patients with severe obesity (BMI $48.0 \pm 2.4$ ) but normal serum creatinine levels who had been subjected to gastroplasty with 9 healthy individuals (BMI $22.2 \pm 0.6$ ) [35]. None of these patients were being treated for diabetes, hypertension or any chronic disease. The study found that a significant weight reduction (BMI down to $32.1 \pm 1.7$ ) within $12-17$ months in the obese subjects was accompanied by a reduction in albuminuria from $16(4-152)$ to $5(3-37) \mu \mathrm{g} / \mathrm{min}(\mathrm{p}<0.01)$. A statistically significant reduction in renal hyperfiltration and systolic blood pressure was also observed. In addition to these case series, there are 2 randomized controlled trials demonstrating the antiproteinuric effect of weight reduction in obese patients, but the numbers are small. A Spanish group randomized 17 obese non-diabetic individuals (BMI $37.9 \pm 4.1)$ with proteinuria $>1$ (mean $3.1 \pm 1.7$ ) $\mathrm{g} /$ day to either a hypocaloric diet $(1,000-4,000 \mathrm{kcal} / \mathrm{day}$ without protein restriction) or captopril (50-150 mg/day) without dietary changes for 1 year [36]. Whilst both groups demonstrated a clear reduction in proteinuria at 1 year, there was a significant correlation between weight reduction and decrease in proteinuria (from $2.9 \pm 1.7$ to $0.4 \pm 0.6 \mathrm{~g} / \mathrm{day}, \mathrm{p}<0.05)$. Another study randomised 30 overweight patients (BMI >27) to a hypocaloric (500 kcal reduction from usual intake) normoproteinic diet (protein content $1-1.2 \mathrm{~g} / \mathrm{kg} /$ day) and control group with no caloric restriction but normoproteinic diet for 5 months [37]. All patients had chronic proteinuric nephropathy of diabetic and non-diabetic causes with proteinuria $>1 \mathrm{~g} /$ day. Drugs with antiproteinuric effects such as ACE inhibitors, angiotensin receptor blockers and non-dihydropyridine calcium channel blockers were withdrawn at least 6 weeks prior to randomization. A significant proteinuria reduction by $31.2 \pm 37 \%$ associated with weight loss $(r=0.62 ; p<0.01)$ was seen in the diet group with the control group showing worsening in proteinuria correlated with significant weight increase. In the secondary analysis, renal function was stable in the diet group, but a significant worsening in creatinine clearance was observed in the control group after 5 months (from $61.8 \pm$ 22.1 to $\left.56 \pm 19.9 \mathrm{ml} / \mathrm{min} / 1.73 \mathrm{~m}^{2}, \mathrm{p}<0.05\right)$. A reduction in weight associated with a decrement in urine albumin excretion was also demonstrated in a recent large $(6,894$ adults) population-based longitudinal study in the Netherlands [38]. No changes in renal function (24-hour urine creatinine clearance) were seen with weight loss during the short follow-up period of 4.2 years. 
The positive association between obesity and kidney disease is a relationship that is both complex and not yet fully understood. High serum leptin levels are found in type 2 diabetic and non-diabetic obese individuals. This is the first adipocyte-derived cytokine (adipokines) to be implicated in the pathogenesis of kidney damage in obesity [39]. Leptin has been shown to stimulate cellular proliferation and expression of prosclerotic TGF- $\beta 1$ cytokine. Normal rats infused with leptin developed proteinuria and focal glomerulosclerosis. Interactions between the activated renin-angiotensin-aldosterone system and leptin appear to play an important role in oxidative stress within endothelial cells and contribute to the pathogenesis of atherosclerosis [40]. Several studies have shown that hyperlipidaemia in itself can contribute to kidney injury [4144]. The obese Zucker (ZDF-fa/fa) rat, which has hyperinsulinaemia and hyperlipidaemia, develops progressive renal failure associated with an accentuated podocyte injury and glomerulosclerosis. Recently, adiponectin (ADPN), another adipokine whose levels are reduced in obesity and insulin resistance, was strongly implicated in the pathogenesis of kidney injury in obesity [45]. In this study by Sharma et al. [45], ADPN-deficient mice exhibited effacement and fusion of podocyte foot processes as well as increased albuminuria. Administration of exogenous ADPN to ADPN null mice led to attenuation in podocyte damage together with a reduction in albuminuria. MS, an increasingly popular entity previously known as syndrome $\mathrm{X}$ [46], is a major consequence of adiposity [47-50]. Large abdominal adiposity is the most important predisposing factor for insulin resistance, which is the hallmark of MS. In such individuals, ADPN are reduced but other proinflammatory adipokines and biomarkers such as interleukin-6, C-reactive protein, tumour necrosis factor $\alpha$ and resistin are elevated. These together with insulin resistance result in the complex metabolic derangements contributing to kidney injury [51-53]. A series of epidemiological studies recently linked fructose ingestion (in the form of table sugar or high-fructose corn syrup) to obesity and MS [54, 55]. In experimental rodents, fructose induced weight gain, hyperinsulinaemia, hypertriglyceridaemia and hyperuricaemia [56]. Uric acid produced following hepatic metabolism of fructose has been implicated in kidney injury $[57,58]$. It causes a reduction in endothelial nitric oxide bioavailability [56], inhibits endothelial cell proliferation $[59,60]$, stimulates release of inflammatory substances $[59,61,62]$, and induces oxidative stress in adipocytes, resulting in impaired ADPN secretion [63]. Hyperuricaemic rats develop renal vasoconstriction, arteriosclerosis and glomerular hypertension $[61,64]$.
Over the past several years, many studies have secured the fundamental importance of adiposity on human health using BMI. While this is the most widely used measure of adiposity, BMI may not be ideal due to its inability to reliably distinguish visceral obesity from subcutaneous fat nor is it able to differentiate a high body weight due to muscle mass from fat (or oedema). Central adiposity reflected by high waist circumference (WC) has been shown to correlate significantly with higher mortality, CVD [65, 66], hypertension, dyslipidaemia and MS compared to BMI [67]. In a recent community-based US population study using creatinine-based models, waistto-hip ratio (WHR) and not BMI was significantly associated with the development of decreased kidney function, even after adjustment for hypertension and diabetes [68]. Likewise, WHR posed a greater CVD risk factor than BMI as demonstrated by a Canadian-led global INTERHEART study [69]. Visceral fat measured by computed tomography [70] was also associated with CVD risk factors more so than BMI in the Framingham Heart Study population. Also, BMI may not be reliably or accurately applicable as the sole index of adiposity throughout communities in Asia. In the Oriental population, central adiposity measured by waist-to-height ratio (WheiR) was the only index of obesity (compared to BMI, WC and WHR) that showed a significant association with CKD (independent of diabetes and hypertension) [71] and urinary albumin excretion rate in type 2 diabetics [72]. Kidney function is presently determined by the estimated glomerular filtration rate (eGFR) using the Modification of Diet in Renal Disease (MDRD) equation adjusted to an average body surface $\left(1.73 \mathrm{~m}^{2}\right)$. However, this equation is imprecise and unreliable in individuals at both extremes of body size [73]. This has led to a proposal to correct eGFR for actual body surface area [74, 75]. Unfortunately, such recalculation in obese patients only resulted in significant underestimation of GFR compared to the absolute GFR measured by $\left[{ }^{51} \mathrm{Cr}\right]$ EDTA [76]. The MDRD formula is derived from a non-obese study population (mean weight of $79.6 \mathrm{~kg}$ ) [73], and it has been argued that any subsequent attempts to correct eGFR to body surface area will never be adequate or valid in obese individuals [76-78]. More studies are required to identify a more reliable measure of kidney function in the obese, but until then use of non-corrected GFR in combination with calibrated serum creatinine has been recommended in these individuals $[76,79]$.

There is now accumulating evidence to suggest that CKD is more common in overweight or obese patients. This association is derived from the currently available 
literature which is largely observational and epidemiological. As such no direct causality link between obesity and CKD can yet be established even though this is highly likely. Many complex factors which include genetic, metabolic, behavioural and environmental factors are responsible for the increasing prevalence in obesity. However, the rapid increase in prevalence suggests that behavioural and environmental influences predominate. Importantly, CKD should be added to the list of complications of overweight and obesity, regardless of whether the association was independent or through the influence of diabetes, hypertension, CVD, MS and high fructose intake. Excess fat stores are an active production site of various inflammatory cytokines, responsible for enhanced levels of inflammation and oxidative stress with detrimental renal effects. This raises the possibility of excess weight or obesity being a potentially modifiable risk factor for development of CKD. Weight-directed therapy along with treatment of diabetes, blood pressure and dyslipidaemia may prove effective in curbing the progression of renal disease and reducing the burden of CKD. However, there are currently no randomized controlled trials with either doubling of serum creatinine or progression to ESRD as primary end-points to suggest obesity as a definite modifiable risk factor for progression or incident cases of CKD. Therefore, large, prospective, randomised weight intervention trials with long-term follow-up, using these end-points to examine the relationship between obesity with onset and progression of $\mathrm{CKD}$, are now urgently needed. These should include obese patients without CKD and those with signs of early CKD. It would be pertinent to use BMI in tandem with other indices of central or visceral adiposity in defining obesity as this may add further prognostic information.

\section{References}

1 Shlipak MG, Fried LF, Cushman M, Manolio TA, Peterson D, Stehman-Breen C, Bleyer A, Newman A, Siscovick D, Psaty B: Cardiovascular mortality risk in chronic kidney disease: comparison of traditional and novel risk factors. JAMA 2005;293:1737-1745.

$\checkmark 2$ Tonelli M, Wiebe N, Culleton B, House A, Rabbat C, Fok M, McAlister F, Garg AX: Chronic kidney disease and mortality risk: systemic review. J Am Soc Nephrol 2006;17: 2034-2047.

- 3 Go AS, Chertow GM, Fan D, McCulloch CE, Hsu CY: Chronic kidney disease and the risks of death, cardiovascular events and hospitalization. N Engl J Med 2004;351: 1296-1305.

4 Iseki K, Ikemiya Y, Fukiyama K: Predictors of end-stage renal disease and body mass index in a screened cohort. Kidney Int 1997;63: S169-S170

$\checkmark 5$ Flegal KM, Carroll MD, Ogden CL, Johnson CL: Prevalence and trends in obesity among US adults, 1999-2000. JAMA 2002;288: $1728-1732$.

6 Craig R, Mindell J (eds): Health Survey for England 2006 Latest Trends (National Statistics): The Information Centre, Joint Health Survey Units: National Centre for Social Research and the Department of Epidemiology and Public Health at the Royal Free and University College Medical School.

7 World Health Organization: Obesity: Preventing and Managing the Global Epidemic: Report of a WHO Consultation on Obesity, Geneva, 1997. Geneva, World Health Organization, 1998.

Overweight, Obesity and Chronic Kidney Disease
8 Kramer H, Luke A, Bidani A, Cao G, Cooper R, McGee D: Obesity and prevalent and incident CKD: the Hypertension Detection and Follow-up Program. Am J Kidney Dis 2005 46:587-594.

-9 Stengel B, Tarver-Carr ME, Powe NR, Eberhardt MS, Brancati FL: Lifestyle factors, obesity and the risk of chronic kidney disease. Epidemiology 2003;14:479-487.

10 Locatelli F, Pozzoni P, Del Vecchio L: Renal manifestations in the metabolic syndrome. Am Soc Nephrol 2006;17:S81-S85.

11 Lee JE, Choi SY, Huh W, Kim YG, Kim DJ, Oh DY: Metabolic syndrome, CRP and chronic kidney disease in nondiabetic, nonhypertensive adults. Am J Hypertens 2007; 20:1189-1194.

12 Chen J, Muntner P, Hamm LL, Jones DW, Batuman V, Fonseca V, Whelton PK, He J: The metabolic syndrome and kidney disease in US adults. Ann Intern Med 2004;140:167174.

13 Kurella M, Lo JC, Chertow GM: The metabolic syndrome and the risk of chronic kidney disease among non-diabetic adults. J Am Soc Nephrol 2005; 16:2134-2140.

14 Hsu CY, McCulloch CE, Iribarren C, Darbinian J, Go AS: Body mass index and risk of end-stage renal disease. Ann Intern Med 2006; 144:21-28.

$\checkmark 15$ Ejerblad E, Fored CM, Lindblad P, Fryzek J, McLauglin JK, Nyren O: Obesity and risk for chronic renal failure. J Am Soc Nephrol 2006; 17:1695-1702.

-16 Fox CS, Larson MG, Leip EP, Culleton B, Wilson PW, Levy D: Predictors of new-onset kidney disease in a community-based population. JAMA 2004;291:844-850.
17 Iseki K, Ikemiya Y, Kinjo K, Inoue T, Iseki C, Takishita S: Body mass index and the risk of development of end-stage renal disease in a screened cohort. Kidney Int 2004;65:18701876.

18 Gelber RP, Kurth T, Kausz AT, Manson JE, Buring JE, Levey AS, Gaziano JM: Association between body mass index and CKD in apparently healthy men. Am J Kidney Dis 2005;46:871-880.

-19 Shankar A, Leng C, Chia KS, Koh D, Tai ES, Saw SM, Lim SC, Wong TY: Association between body mass index and chronic kidney disease in men and women: populationbased study of Malay adults in Singapore. Nephrol Dial Transplant 2008;23:19101918.

20 Clinical Guidelines on the Identification, Evaluation and Treatment of Overweight and Obesity in Adults: The Evidence Report. NIH Publ No. 98-4083. Bethesda, National Institutes of Health, 1998.

21 Bonnet F, Deprele C, Sassolas A, et al: Excessive body weight as a new independent risk factor for clinical and pathological progression in primary IgA nephritis. Am J Kidney Dis 2001;37:720-727.

22 Ducloux D, Kazory A, Simula-Faivre D, Chalopin JM: One-year posttransplant weight gain is a risk factor for graft loss. Am J Transplant 2005;5:2922-2928.

23 Meier-Kriesche HU, Arndorfer JA, Kaplan B: The impact of body mass index on renal transplant outcomes: a significant independent risk factor for graft failure and patient death. Am J Transplant 2001(suppl 2):5859 . 
24 Praga M, Hernandez E, Herrero JC, et al: Influence of obesity on the appearance of proteinuria and renal insufficiency after unilateral nephrectomy. Kidney Int 2000;58: 2111-2118.

25 Lane JT: Microalbuminuria as a marker of cardiovascular and renal risk in type 2 diabetes mellitus: a temporal perspective. Am J Physiol Renal Physiol 2004;286:F442-F450.

26 Hall JE: The kidney, hypertension and obesity. Hypertension 2003;41:625-633.

27 Chagnac A, Weinstein T, Korzets A, Ramadan E, Hirsch J, Gafter U: Glomerular hemodynamics in severe obesity. Am J Physiol Renal Physiol 2000;278:F817-F822.

28 Chen HM, Li SJ, Chen HP, Wang QW, Li LS, Liu ZH: Obesity-related glomerulopathy in China: a case series of 90 patients. Am J Kidney Dis 2008;52:58-65.

29 Praga M, Hernandez E, Morales E, Campos AP, Valero MA, Martinez MA, Leon M: Clinical features and long-term outcome of obesity-associated focal segmental glomerulosclerosis. Nephrol Dial Transplant 2001; 16:1790-1798.

-30 Kambham N, Markowitz G, Valeri AM, Lin J, D’Agati VD: Obesity-related glomerulopathy: an emerging epidemic. Kidney Int 2001; 59:1498-1509.

- 31 Adelman RD, Restaino IG, Alon US, Blowey DL: Proteinuria and focal segmental glomerulosclerosis in severely obese adolescents. J Pediatr 2001;138:481-485.

-32 Kambham N, Markowitz GS, Valeri AM, Lin J, D’Agati VD: Obesity-related glomerulopathy: an emerging epidemic. Kidney Int 2001; 59:1498-1509.

- 33 Govindarajan G, Whaley-Connell A, Mugo M, Stump C, Sowers JR: The cardiometabolic syndrome as a cardiovascular risk factor. Am J Med Sci 2005;330:311-318.

- 34 Ohashi H, Oda H, Ohno M, Watanabe S: Weight reduction improves high blood pressure and microalbuminuria in hypertensive patients with obesity (in Japanese). Nippon Jinzo Gakkai Shi 2001;43:333-339.

- 35 Chagnac A, Weinstein T, Herman M, Hirsh J, Gafter U, Ori Y: The effects of weight loss on renal function in patients with severe obesity. J Am Soc Nephrol 2003;14:14801486.

36 Praga M, Hernandez E, Andres A, Leon M, Ruilope LM, Rodicio JL: Effects of bodyweight loss and captopril treatment on proteinuria associated with obesity. Nephron 1995;70:35-41.

-37 Morales E, Valero MA, Leon M, Hernandez E, Praga M: Beneficial effects of weight loss in overweight patients with chronic proteinuric nephropathies. Am J Kidney Dis 2003; 41:319-327.

38 Bello AK, de Zeeuw D, El Nahas M, Brantsma AH, Bakker SJL, de Jong PE, Gansevoort RT: Impact of weight change on albuminuria in the general population. Nephrol Dial Transplant 2007;22:1619-1627.
39 Wolf G, Hamman A, Han DC, Helmchen U, Thaiss F, Zyyadeh FN, Stahl RA: Leptin stimulates proliferation and TGF- $\beta$ expression in renal glomerular endothelial cells. Potential role in glomerulosclerosis. Kidney Int 1999;56:860-872.

40 Correia ML, Haynes WG: Leptin, obesity and cardiovascular disease. Curr Opin Nephrol Hypertension 2004;13:215-223.

41 Hoshi S, Shu Y, Yoshida F, Inagaki T, Sonoda J, Watanabe T, Nomoto K, Nagata M: Podocyte injury promotes progressive nephropathy in Zucker diabetic fatty rats. Lab Invest 2002;82:25-35.

-42 Keane WF: Lipids and the kidney. Kidney Int 1994;46:910-920.

43 Joles JA, Kunter U, Janssen U, Kriz W, Rabelink TJ, Koomans HA, Floege J: Early mechanisms of renal injury in hypercholesterolemic or hypertriglyceridemic rats. J Am Soc Nephrol 2000;11:669-683.

44 Weinberg JM: Lipotoxicity. Kidney Int 2006; 70:1560-1566.

45 Sharma K, Ramachandrarao S, Qiu G, Usui HK, Zhu Y, Dunn SR, Ouedraogo R, Hough K, McCue P, Chan L, Falkner B, Goldstein BJ: Adiponectin regulates albuminuria and podocyte function in mice. J Clin Invest 2008;118:1645-1656.

46 Reaven GM: Role of insulin resistance in human disease. Diabetes 1988;37:1595-1607.

47 Ford ES, Giles WH, Mokdad AH: Increasing prevalence of the metabolic syndrome among US adults. Diabetes Care 2004;27: 2444-2449.

48 Chen J, Gu D, Chen CS, Wu X, Hamm LL, Muntner P, Batuman V, Lee CH, Whelton PK, He J: Association between the metabolic syndrome and chronic kidney disease in Chinese adults. Nephrol Dial Transplant 2007;22:1100-1106.

49 Kitiyara C, Yamwong S, Cheepudomwit S, Domrongkitchaiporn S, Unkurapinun N, Pakpeankitvatana V, Sritara P: The metabolic syndrome and chronic kidney disease in a Southeast Asian cohort. Kidney Int 2007;71: 693-700.

50 Rashidi A, Ghanbarian A, Azizi F: Are patients who have metabolic syndrome without diabetes at risk for developing chronic kidney disease? Evidence based on data from a large cohort screening population. Clin J Am Soc Nephrol 2007;2:976-983.

51 Wisse BE: The inflammatory syndrome: the role of adipose tissue cytokines in metabolic disorders linked to obesity. J Am Soc Nephrol 2004;15:2792-2800.

52 Ramkumar N, Cheung AK, Papas LM, Roberts WL, Beddhu S: Association of obesity with inflammation in chronic kidney disease: a cross-sectional study. J Ren Nutr 2004; 14:201-207.

53 Wu Y, Liu Z, Xiang Z, Zeng C, Chen Z, Ma X, Li L: Obesity-related glomerulopathy: Insights from gene expression profiles of the glomeruli derived from renal biopsy samples. Endocrinology 2006; 147:44-50.
54 Bray GA, Nielsen SJ, Popkin BM: Consumption of high-fructose corn syrup in beverages may play a role in the epidemic of obesity. Am J Clin Nutr 2004;79:537-543.

55 Schulze MB, Manson JE, Ludwig DS, Colditz GA, Stampfer MJ, Willett WC, Hu FB: Sugarsweetened beverages, weight gain, and incidence of type 2 diabetes in young and middle-aged women. JAMA 2004;292:927-934.

56 Nakagawa T, Hu H, Zharikov F, Tuttle KR, Short RA, Glushakova O, Ouyang X, Feig DI, Block ER, Herrera-Acosta J, Patel JM, Johnson RJ: A causal role for uric acid in fructoseinduced metabolic syndrome. Am J Physiol Renal Physiol 2006;290:F625-F631.

57 Iseki K, Oshiro S, Tozawa M, Iseki C, Ikemiya Y, Takishita S: Significance of hyperuricemia on the early detection of renal failure in a cohort of screened subjects. Hypertens Res 2001;24:691-697.

58 Siu YP, Leung KT, Tong MK, Kwan TH: Use of allopurinol in slowing the progression of renal disease through its ability to lower serum uric acid level. Am J Kidney Dis 2006; 47:51-59.

59 Kang DH, Park SK, Lee IK, Johnson RJ: Uric acid-induced C-reactive protein expression: implication on cell proliferation and nitric oxide production of human vascular cells. J Am Soc Nephrol 2005; 16:3553-3562.

60 Khosla UM, Zharikov S, Finch JL, et al: Hyperuricemia induces endothelial dysfunction. Kidney Int 2005;67:1739-1742.

61 Mazzali M, Kanellis J, Han L, Feng L, Xia YY, Chen Q, Kang DH, Gordon KL, Watanabe S, Nakagawa T, Lan HY, Johnson RJ: Hyperuricemia induces a primary renal arteriolopathy in rats by a blood pressure-independent mechanism. Am J Physiol Renal Physiol 2002;282:F991-F997.

62 Rao GN, Corson MA, Berk BC: Uric acid stimulates vascular smooth muscle cell proliferation by increasing platelet-derived growth factor A-chain expression. J Biol Chem 1991;266:8604-8608.

63 Sautin Y, Nakagawa T, Zharikov S, Johnson RJ: Adverse effects of the classic antioxidant uric acid in adipocytes: NADPH oxidasemediated oxidative/nitrosative stress. Am J Physiol Cell Physiol 2007;293:C584-C596.

64 Sanchez-Lozada LG, Tapia E, Avila-Casado C, Soto V, Franco M, Santamaria J, Nakagawa T, Rodriguez-Iturbe B, Johnson RJ, Herrera-Acosta J: Mild hyperuricemia induces glomerular hypertension in normal rats. Am J Physiol Renal Physiol 2002;283:F1105F1110.

65 Rexrode KM, Carey VJ, Hennekens CH, Walters EE, Colditz GA, Stampfer MJ, Willett WC, Manjon JE: Abdominal adiposity and coronary heart disease in women. JAMA 1998;280:1843-1848.

66 Kuk JL, Katzmarzyk PT, Nichaman MZ, Church TS, Blair SN, Ross R: Visceral fat is an independent predictor of all-cause mortality in men. Obes Res 2006;14:336-341. 
67 Janssen I, Katzmarzyk PT, Ross R: Waist circumference and not body mass index explains obesity-related health risk. Am J Clin Nutr 2004;79:379-384.

-68 Elsayed EF, Sarnak MJ, Tighiouart H, Griffith JL, Kurth T, Salem DN, Levey AS, Weiner DE: Waist-to-hip ratio, body mass index, and subsequent kidney disease and death. Am J Kidney Dis 2008;52:29-38.

-69 Yusuf S, Hawken S, Ounpuu S, Bautista L, Franzosi MG, Commerford P, Lang CC, Rumboldt Z, Onen CL, Lisheng L, Tanomsup S, Wangai P Jr, Razak F, Sharma AM, Anand SS: Obesity and the risk of myocardial infarction in 27,000 participants from 52 countries: a case-control study. Lancet 2005; 366:1640-1649.

70 Fox CS, Massaro JM, Hoffmann U, Pau KM, Maurovich-Horvat P, Liu CY, Vasan RS, Murabito JM, Meigs JB, Cupples LA, D’Agostino RB Sr, O’Donnell CJ: Abdominal visceral and subcutaneous adipose tissue compartments: association with metabolic risk factors in Framingham Heart Study. Circulation 2007;116:39-48.
71 Lin CH, Chou CY, Lin CC, Huang CC, Liu CS, Lai SW: Waist-to-height ratio is the best index of obesity in association with chronic kidney disease. Nutrition 2007;23:788-793.

72 Tseng CH: Waist-to-height ratio is independently and better association with urinary albumin excretion rate than waist circumference or waist-to-hip ratio in Chinese adult type 2 diabetic women but not men. Diabetes Care 2005;28:2249-2251.

73 Levey AS, Coresh J, Balk E, Kausz AT, Levin A, Steffes MW, Hogg RJ, Perrone RD, Lau J, Eknoyan G: National Kidney Foundation practice guidelines for chronic kidney disease: evaluation, classification, and stratification. Ann Intern Med 2003;139:137-147.

$\checkmark 74$ Peters AM, Henderson BL, Lui D: Indexed glomerular filtration rate as a function of age and body size. Clin Sci (Lond) 2000;98:439444 .
5 Shuter B, Aslani A: Body surface area: Du Bois and Du Bois revisited. Eur J Appl Physiol 2000;82:250-254.

76 Delanaye P, Radermecker RP, Rorive M, Depas G, Krzesinski JM: Indexing glomerular filtration rate for body surface area in obese patients is misleading: concept and example. Nephrol Dial Transplant 2005;20:20242028.

77 Schmieder RE, Beil AH, Weihprecht H, Messerli FH: How should renal hemodynamic data be indexed in obesity? J Am Soc Nephrol 1995;5:1709-1713.

-78 Anastasio P, Spitali L, Frangiosa A, Molino D, Stellato D, Cirillo E, Pollastro RM, Capodicasa L, Sepe J, Federico P, Gaspare De Santo N: Glomerular filtration rate in severely overweight normotensive humans. Am J Kidney Dis 2000;35:1144-1148.

79 Coresh J, Eknoyan G, Levey AS: Estimating the prevalence of low glomerular filtration rate requires attention to the creatinine assay calibration. J Am Soc Nephrol 2002;13:28112812.

\title{
Editorial Comment
}

\author{
M. El Nahas, Sheffield
}

This minireview by Stephen Ting from Indranil Dasgupta's group in Birmingham UK is a timely reminder of the links and associations between obesity and CKD. Globally, obesity is on the rise with more than a billion individuals worldwide suffering from overweight and obesity. Over the years, it has been widely appreciated that obesity is associated with obesity-related glomerulopathy and nephropathy characterised by proteinuria and focal segmental glomerulosclerosis. More recently, however, obesity is becoming a central focus of the global impression of an increased prevalence of CKD. Microalbuminuria is more common in obese individuals and recent observations suggest that such an association is dependent on obesity-associated inflammation and that microalbuminuria is reversible upon weight loss [1]. Also growing evidence has linked obesity and the associated metabolic syndrome to the incidence of CKD; some have suggested that such an association is more readily detectable with central obesity. We drew attention to issues re- lated to poverty and CKD; obesity is strongly associated in some communities with social deprivation and limited access to healthy diet and exercise [2]. Clearly, more attention needs to be paid worldwide to stem the tide of obesity and the associated metabolic syndrome and diabetes. They are at the centre of the global rise of chronic non-communicable diseases and a number of initiatives have been taken by governments worldwide to address obesity and its impact on non-communicable diseases including CKD.

\section{References}

$\checkmark 1$ Bello AK, Peters J, Wight J, de Zeeuw D, El Nahas M; European Kidney Institute: A population-based screening for microalbuminuria among relatives of CKD patients: the Kidney Evaluation and Awareness Program in Sheffield (KEAPS). Am J Kidney Dis 2008;52:434-443.

-2 Hossain MP, Goyder EC, Rigby JE, El Nahas M: CKD and poverty: a growing global challenge. J Kidney Dis 2009;53:166-174. 